\title{
Conducting polymer actuator driven catheter: overview and applications
}

\author{
Tina Shoa ${ }^{1}$, Nigel.R Munce ${ }^{2,}$ Victor Yang ${ }^{2}$, John D. Madden ${ }^{1}$ \\ ${ }^{1}$ Department of Electrical Engineering, University of British Columbia \\ ${ }^{2}$ Sunnybrook and Women's Health Sciences Ctr. Toronto
}

\begin{abstract}
In this paper conducting polymer based active catheters are presented. Design considerations along with the promise and challenges associated with conducting polymer driven devices are discussed. A conducting polymer driven intravascular catheter is described briefly and its design challenges such as structural rigidity and angle of bending are studied. Then a detailed description of a polypyrrole based active catheter that is ultimately intended for in-vivo imaging applications will be presented. The active catheter contains an optical fibre and is designed to scan the fibre in two dimensions at a speed of $30 \mathrm{~Hz}$ to provide real time imaging. The preliminary design was realized by fabricating polypyrrole actuators on a commercially available catheter and patterning the polymer using laser machining technique. The initial device was tested at lower speeds and an image was taken using optical coherence tomography (OCT). The primary challenge to achieving an effective polypyrrole driven catheter for real time imaging is to demonstrate high speed actuation with reasonable liftetime. According to our model, electrochemical characteristics of the conducting polymer such as electronic conductivity, ionic conductivity and electrochemical strain need to be improved to achieve the desired catheter scanning speed.
\end{abstract}

Keywords: conducting polymer, active catheter, polypyrrole actuator

\section{INTRODUCTION}

Catheterization is a common medical procedure, in which a hollow tube (i.e. the catheter) is inserted into body cavities to provide a channel for fluid passage or an entry for a medical device. Catheters as fluid channels may be used to drain urine from the urinary bladder and administrate the intravenous fluids and medication directly into the body. Catheters are also used to direct a medical tool to a particular part of the body for minimally invasive surgical procedures. In angioplasty, for instance, catheters are employed to guide a therapeutic device to open a blockage inside a blood vessel [1].

The conventional method of handling a catheter involves inserting it into the body passively by employing push/pull control mechanism that is outside the body, where a wire configured to be pushed or pulled along a longitudinal axis to bend the catheter tip [2]. Limitations of the current catheter and guidewire designs include long procedural times, and risk of lumen or vessel wall damage, both as a result of slow and inexact guidance. These issues become more critical when dealing with narrow and complex passages such as blood vessels of the brain and tertiary bronchi of the lung [1]. Therefore, advanced active catheter designs with controllable features are required in order to enhance the performance of these devices during minimally invasive medical procedures. Various active catheters driven by different methods have been suggested, however no active catheters are in wide spread use. Micromotors mounted catheters had been reported for ultrasonography [3,4] ,but they feature a relatively large size (diameter of $1.9 \mathrm{~mm}$ [4]) and expensive fabrication process. Shape memory alloy (SMA) and Shape Memory Polymers (SMP) actuators have been used for steerable endoscopes [5-11]. Although these types of actuators are potentially able to provide a large degree of bending, their slow response, high operating temperature and the possibility of electrical current leakage limit their applications [9]. Controllable catheters utilizing hydraulic mechanisms have also been developed, where the catheter position is controlled by varying the size of inflatable balloons mounted on its tip using electro-thermally controlled microvalves [2]. This mechanism is cumbersome and controlling the microvalves is slow; hence not suitable for many applications [1]. Ionic Polymer Composites (IPMC) actuator has been also suggested to design active catheters [12-14]. These actuators can generate large displacements at relatively low voltages $(<10 \mathrm{~V})$ and moderate speed; however, their manufacturing process is often relatively expensive and additional energy is usually consumed for holding the actuator

Electroactive Polymer Actuators and Devices (EAPAD) 2009, edited by Yoseph Bar-Cohen, Thomas Wallmersperger, Proc. of SPIE Vol. 7287, 72871J · C 2009 SPIE · CCC code: 0277-786X/09/\$18 · doi: 10.1117/12.816039 
in a position. Conducting polymer actuators have shown attractive properties, which make them promising to be employed extensively in active catheter applications. Some of the characteristics include low actuation voltage, ease of fabrication, relatively high strain, and biocompatibility. In this paper general catheter design considerations are first briefly described. Then the applications of conducting polymer actuators in active catheters are discussed. Performance specifications along with potential applications are presented, and recent active catheter prototypes are described. Then a detailed description of a polypyrrole based active catheter that is ultimately intended for in-vivo imaging applications will be presented. The promise and challenges associated with conducting polymer driven devices are discussed.

\section{CATHETER DESIGN CONSIDERATIONS}

The first obvious requirement of active catheters is their biocompatibility and safe operating conditions. Issues such as toxicity, biolayer formation and operating current, voltage, temperature and power must be carefully investigated [1]. There are, however, cases of active element containing non-biocompatible features, in which encapsulation with a biomaterial is mandated [1]. The heart is particularly sensitive to currents, and the American Heart Association has guidelines to be considered in the design of active catheters used in cardiovascular applications [15].

In order to minimize the size of the patient's entry wound from a minimally invasive procedure, catheters with smaller size are desirable. In addition advanced medical treatment and diagnosis procedures require micro-sized catheters to reach the micro-sized arteries, which are not accessible in conventional catheterizations [1].

It is also important to design low cost active catheters to minimize the cost of minimally invasive intervention procedures. This is, however, challenging since micro-devices comprise complicated and expensive fabrication procedures. Thus choosing a cost effective fabrication method as well as low cost active element materials become key factors in designing practical active catheters [1].

Structural rigidity of the catheter is another factor to be considered, since a certain optimum structural rigidity is required for certain applications. For instance cardiovascular guide wire/catheter structures should have sufficient axial rigidity along the length of the blood vessels to enable penetration without collapsing and high torsional rigidity to provide a controlled twist for proper manipulation [16]. The end of the structure, however, may possess low flexural rigidity in order to move in the tortuous sections of the cardiovascular system. As another example, mapping cardiovascular catheters, which are designed for stimulating and monitoring electrical activity, should be highly rigid to tolerate the turbulent conditions of the interior of the heart [17]. Thus an active element embedded on the passive catheters (such as a conducting polymer for controlled bending) needs to satisfy the catheter rigidity requirements for the desired application [1].

\section{CONDUCTING POLYMER ACTUATOR BASED ACTIVE CATHETERS}

Conducting polymer $(\mathrm{CP})$ actuators are relatively new types of actuators, which exhibit electrochemically controllable electronic conductivities $\left(10^{4}-10^{5} \mathrm{~S} / \mathrm{m}\right)$ [18]. Polypyrrole and polyaniline are the most common conducting polymers used as actuators with the elastic moduli of typically $>0.2 \mathrm{GPa}$ [33]. These polymers are typically semiconductors which can be doped to reach nearly metallic conduction. Doping involves the addition (oxidation) or removal (reduction) of charges from the polymer chain, which result in expansion or contraction of the polymer structure. Figure 1a shows polypyrrole electrochemical doping, inside an ionic electrolyte and Figure 1b illustrates the mechanism of the dimensional change as a result of the electrochemical activation. As shown in the figure a substrate (here a catheter) coated with conducting polymer electrodes on both sides (i.e forming a trilayer) is in an electrolyte solution containing mobile negative ions and large immobile positive ions. An alternating voltage is applied across the two polymer electrodes resulting in alternating oxidation and reduction of the polymer electrodes. During oxidation the mobile negative ions enter the polymer from the electrolyte, therefore expand the structure. During reduction they exit the polymer to the electrolyte and contract it. Expansion on one side and contraction on the other side induces a stress gradient on the polymer/catheter interfaces and causes the whole structure to bend in one direction. Alternating expansion and contraction will result in the movement of the catheter in 2 dimensions inside the electrolyte solution.

The electrolyte can also be in the form of a gel (i.e. a solution of metal salts trapped in a cross-linked soluble polymer matrix) or a solid (i.e a complex of high molecular weight polymers and metal salts) [19], in which cases, the electrolyte itself is part of the moving structure.

Proc. of SPIE Vol. 7287 72871J-2 


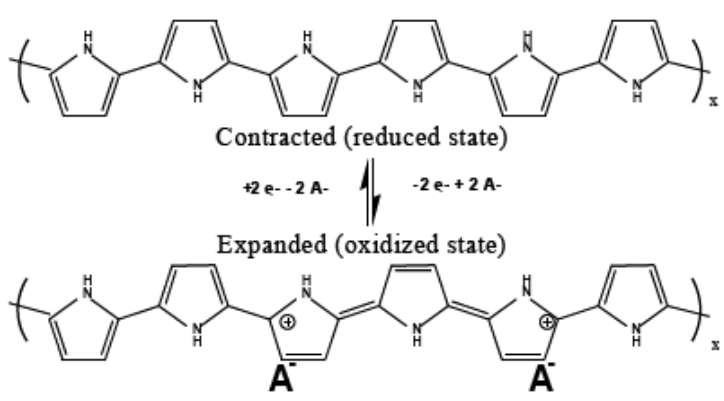

(a)

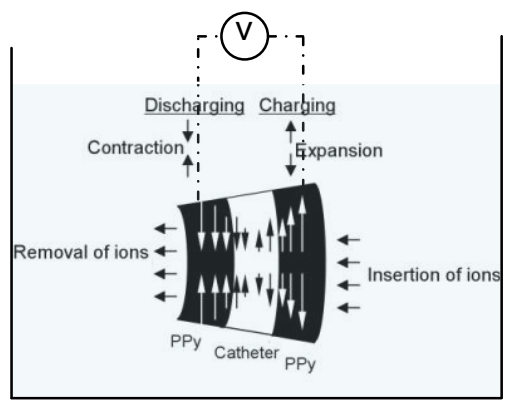

(b)

Figure 1 a: Electrochemical doping of polypyrrole with mobile anions. A` represent anions, e electrons.b: Stress distribution upon insertion and removal of ions from the polypyrrole layer. If small cations are present with large anions the direction of ion flux and actuation is inverted (Adapted from [20]).

Conducting polymer actuators are good candidates for driving active catheters, due to their low voltage $(<1 \mathrm{~V})$, high strain (typically $2 \%$ or greater), low cost and biocompatibility [18]. The relatively high stiffness of these materials (elastic moduli of 1GPa [33]), also makes them suitable for use as active catheter drive elements [1].

\subsection{Conducting polymer in intravascular catheters}

Della Santa et al have proposed conducting polymer driven catheter designs for intravascular application [21,22]. The designed active catheters require to have a bending stiffness of at least $5 \mathrm{~N} / \mathrm{m}$ and a response time of the order of seconds and are expected to produce a bending angle of at least $20^{\circ}$. They suggested two different designs and compared their performances using finite element simulation. The first design is composed of a solid polymer electrolyte (SPE) sandwiched between two conducting polymer (CP) actuators, which are inserted inside the catheter walls (Figure 2a). The expansion or contraction of the CP layer makes the multilayer bend, and this bending is transferred to the structure of the catheter [21]. The second design is composed of a catheter whose wall is fabricated from an active composite of conducting polymer fibres embedded in an SPE elastometric matrix (see Figure 2b) [22]. Figure 2c illustrates the operation of the second proposed catheter, in which two opposite electrochemical stimuli are applied across the upper and lower sectors of the cylinder ( $\Delta \phi=135^{\circ}$ sectors shown in the figure), one causes contraction of the fibres in the upper half of the structure, while the other causes expansion of the lower fibres, leading the catheter tip to bend upwards in this case [22].

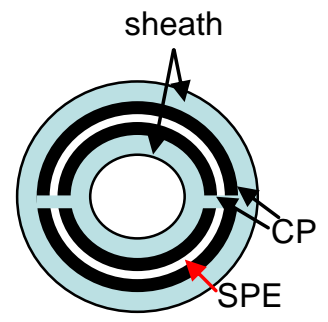

(a)

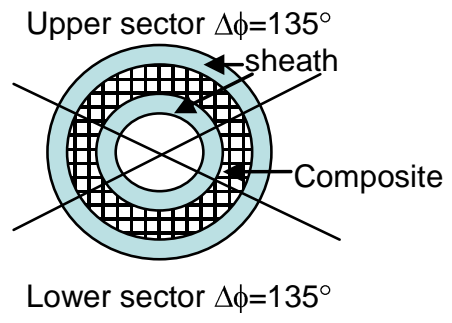

(b)

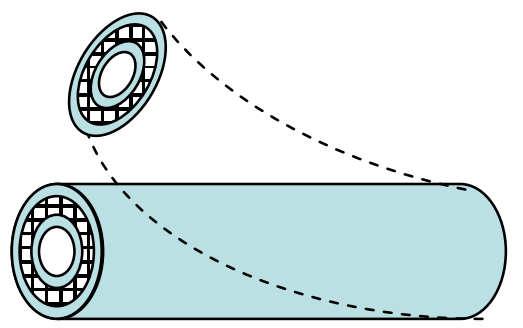

(c)

Figure 2: schematic of the device (a) first design consists of CP/SPE/CP sandwich structure inserted inside the catheter wall [22], (b) distributed actuator fibre +SPE, (c) functioning device (adapted from [19]).

According to the simulation results, the second configuration (Figure 2b) offers the best performance both in terms of bending degree $\left(17.2^{\circ}\right)$ and bending stiffness $(0.81 \mathrm{~N} / \mathrm{m})$ than the first configuration $\left(11.7^{\circ}\right.$ and $\left.0.19 \mathrm{~N} / \mathrm{m}\right)$ [22]. The authors proposed increasing the fraction of composite material inside the walls of the catheter and incorporating Polyaniline fibres doped with perchlorate ions as the conducting polymer element to improve the rigidity [21,22]. The thickness of the $\mathrm{CP}$ is an important factor determining the actuator response time, and since the fibres can be much 
smaller than the films, they may also be faster [12]. According to the simulation, CP fibres with diameters of less than 10 $\mu \mathrm{m}$ are likely needed in order to obtain the required actuation speed [12]. The active catheter proposed in [19,21,22] is able to reach through arteries with path angle of less than $20^{\circ}$, however, a more complicated design capable of producing larger angle of bending is needed in order to access tortuous regions of cardiovascular systems [1].

\subsection{Conducting polymer in OCT fast scanning catheter}

We present an active catheter design similar to those of Mazzoldi, De Rossi and colleagues that are described in the previous section, but employed to rapidly scan the tip of the catheter to enable high-resolution 3D imaging via optical coherence tomography (OCT). In-vivo imaging of internal body tissues using OCT catheters has a number of potential applications, including the diagnosis and monitoring the progression of vascular diseases [23]. Forward-looking images from the inside of the blood vessels can be useful for navigating catheters during interventational procedures. Due to the size and the torturous nature of the blood vessels, fibre bundle based systems are typically not compatible for clinical applications in the brain or heart. Optical Coherence Tomography is an emerging imaging technique that permits threedimensional high-resolution visualization of subsurface tissue [24]. It can serve as an important diagnostic adjunct, enabling the detection and the monitoring of changes in tissues, may be useful for assessment of vascular disease and cancer tissue progression [25], and surgical guidance. OCT performs depth resolved imaging by sending wide band near infrared light into tissue and observing the backscattered light interferometrically [25].

One of the common designs currently employed by intravascular OCT uses a rotating fibre driven by an external motor. The fibre tip contains miniature focusing and beam bending optics such that rotation of the tip provides circumferential scanning of the optical beam in a side viewing geometry [17]. Physical displacement of a catheter hosting the fibre through the arteries, coupled with the rotational motion, provides 3D cylindrical scanning. A limitation of this approach is the lack of imaging information distal to the tip of the catheter (i.e. in front of it), which may be addressed by a forward-viewing design. Forward viewing will enable imaging of occlusions for example [1].

Y.Wang et.al, has developed a hand-held OCT probe incorporated with IPMC actuator for clinical oral and skin exvivo imaging [32]. An optical fibre was directly attached to the IPMC actuator such that the bending vibration of the IPMC generates a scanning movement of the optical beam. The fibre is scanned by $3 \mathrm{~mm}$ through the IPMC actuator with the applied voltage of $2 \mathrm{~V}$ at $1 \mathrm{~Hz}$ [32]. We have designed a polypyrrole actuator for scanning an optical fibre in 2 dimensions for in-vivo imaging application. The desired scan area is $1 \mathrm{~mm}^{2}$, at a relatively high speed $(10-30 \mathrm{~Hz}$ per line scan) and over 50,000 cycles for intravascular OCT imaging application. The design is composed of a four-electrode polymer actuator, which is fabricated directly on a commercial catheter tip. The catheter used to demonstrate the bending is Micro Therapeutics Inc. (Irvine, CA) Ultraflow ${ }^{\mathrm{TM}} \mathrm{HPC}(0.5 \mathrm{~mm} \mathrm{OD} / 0.28 \mathrm{~mm}$ ID) where the final $25 \mathrm{~mm}$ is coated with active polymer. The complete device is a catheter whose active tip is encapsulated inside a structure containing an ionic electrolyte (Figure 3). The device is electrochemically actuated inside the ionic electrolyte in two dimensions using voltage changes of $<1 \mathrm{~V}$ per polymer electrode. Actuation is associated with the insertion or removal of ions to or from the polymer as was explained earlier. The encapsulation ensures that currents needed to drive the actuation are isolated from nearby tissue, and provides an optimal electrolyte for achieving large and fast actuation. A lens is embedded at the end of the encapsulation tube, which can amplify the angular scanning range [1].

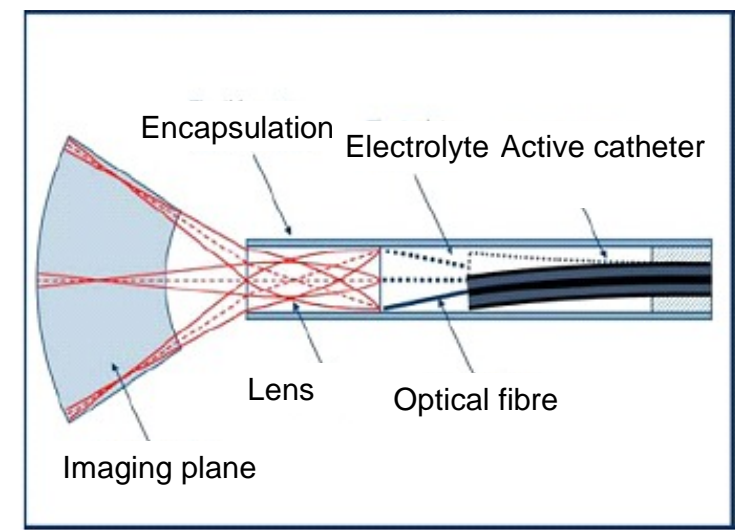

Figure 3: Schematics of the active-OCT imaging catheter, where an optical fibre is scanned by the polymer actuator and a lens focuses the light at the imaging plane. The reflected light is collected by the same optical fibre and processed by the OCT system (Copyright (2009) John Wiley \& Sons, Inc.). 
The active element fabrication involves chemical deposition of polymer onto the catheter followed by an electrochemical deposition. Chemical deposition is performed by polymerization of pyrrole monomer in the presence of an oxidizing agent. The oxidizing solution contains $0.413 \mathrm{ml}$ of $12.1 \mathrm{M} \mathrm{HCl}$ and $1.2 \mathrm{~g}$ of $\mathrm{FeCl}_{3}$ in $50 \mathrm{ml}$ of water. The monomer solution contains $0.1 \mathrm{M}$ of pyrrole. Deposition is achieved by alternately dipping the sample in each of the two solutions until the desired thickness of polymer forms. This process results in a thin polymer with a conductivity of $\sim 10^{3}$ $\mathrm{S} / \mathrm{m}$, which is sufficient to be used as a seed layer in electrochemical deposition. Polypyrrole films are grown from a solution of $0.06 \mathrm{M}$ pyrrole monomer and $0.05 \mathrm{M}$ tetraethylammonium hexafluorophosphate and $1 \%$ vol distilled water in propylene carbonate, following the procedure of Yamaura [26]. Polypyrrole is deposited galvanostatically on to electrically conductive substrates at current density of $1.25 \mathrm{~A} / \mathrm{m}^{2}$ and at temperatures between $-30{ }^{\circ} \mathrm{C}$ and $-45^{\circ} \mathrm{C}$. Four longitudinal stripes are then cut into the polymer coating via laser ablation to produce four electrodes [1] (Figure 4).

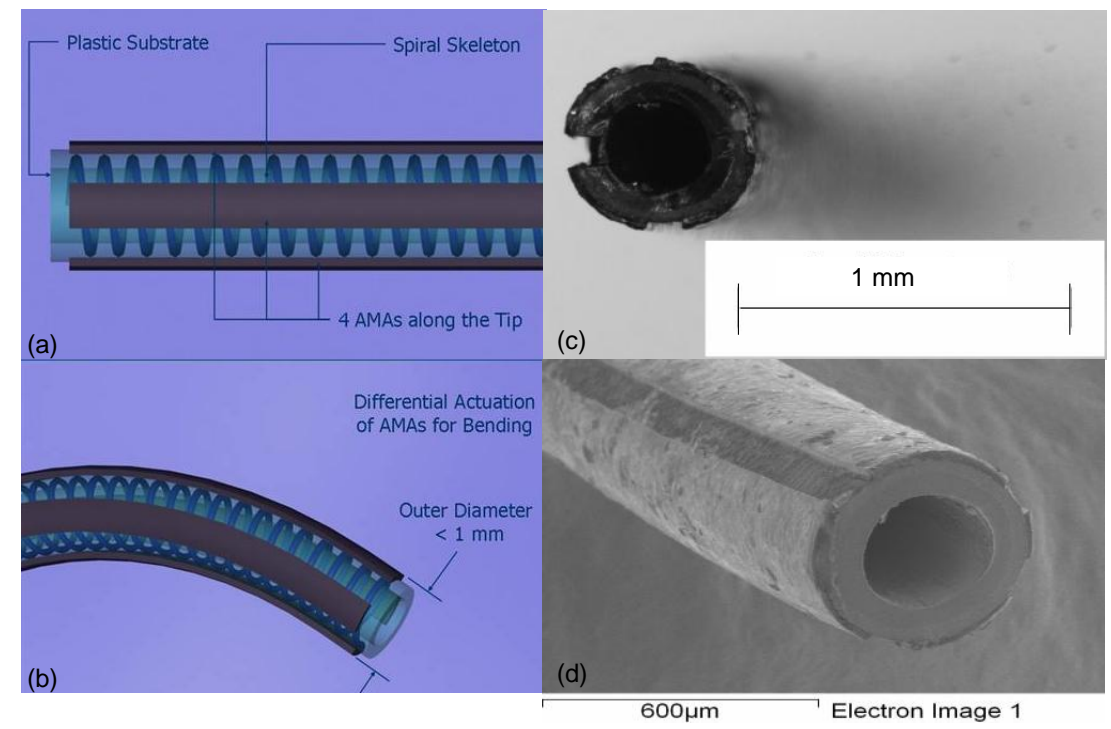

Figure 4: illustration of design and prototypes of 4 segment conducting polymer electrodes for 2-dimensional motion (Copyright (2009) John Wiley \& Sons, Inc.).

Effective patterning of the polypyrrole electrodes, shown in Figure 4, is critical to the success of this design. Patterning of polypyrrole electrodes has previously been achieved using photolithography [27], but this method is not practical for non-planar geometries. Instead laser micromachining was employed. It is a mature technology for shaping tubular structures such as laser cut stents. Excimer laser micromaching, in particular, is very well established as a tool for machining of polymers. Excimer laser ablation at $248 \mathrm{~nm}$ was used to pattern polypyrrole on the coated catheters. (Kr:F excimer laser, GSI Lumonics plus beam expansion optics, a photomask, focusing optics, and an xyz programmable stage.) An important benefit of using ablation is that there is no thermal damage and minimal debris, as is evident in the clean cut [1].

A preliminary image was obtained by inserting a ball-lensed fibre optic into the polypyrrole based active catheter. The fibre was connected to a commercially available OCT system (Figure 5a). The scanning angle using the ball-lens is smaller than using a larger lens, such as gradient index lenses [28]. 


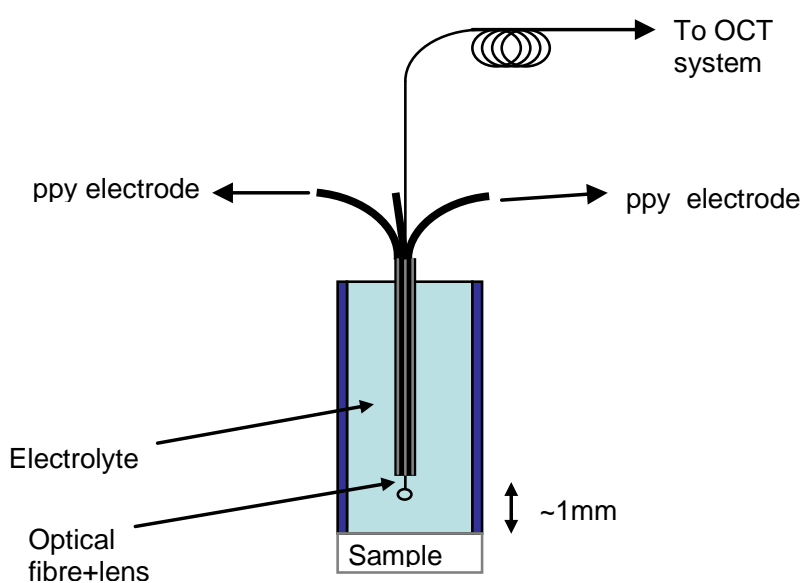

(a)

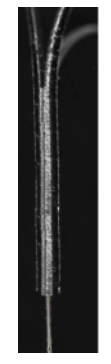

(b)

Figure 5: (a) Schematic of the actuator set up for OCT imaging. (b) Image of the catheter hosting an optical fibre (Copyright (2009) John Wiley \& Sons, Inc.).

The primary demonstration of the device was performed with a speed of $10 \mathrm{~Hz}$. In order to achieve this frequency response a relatively large overvoltage was needed, with the total applied voltage reaching $10 \mathrm{~V}$. The acquired image was comparable to the images taken using the conventional motor based fibre scanning method. However, the number of scanning cycles was limited due to short polymer lifetime at high actuation voltages. Therefore design modification is required in order to achieve both high speed of actuation and the desired polymer life cycle of >50,000 [1].

A dynamic electromechanical model was developed to simulate the actuation behaviour of the active catheter, and was used to study the feasibility of achieving high speed actuation $(10 \mathrm{~Hz}-30 \mathrm{~Hz})$ appropriate for OCT imaging. The model consists of a flexible tube (catheter) with inner and outer diameters of $b=280 \mu \mathrm{m}$ and $\mathrm{a}=500 \mu \mathrm{m}$ with $10 \mu \mathrm{m}$ thick polypyrrole coating as the active element. According to the model, a polymer thicknesses of $\sim 10 \mu \mathrm{m}$ results in maximum tip displacement at high frequencies $(10-30 \mathrm{~Hz})$. The Young's modulus of a $10 \mu \mathrm{m}$ thick electrochemically grown polypyrrole film and a commercially available catheter were measured to be $0.3 \mathrm{GPa}$ and $75 \mathrm{MPa}$ respectively. The polypyrrole active strain, $\varepsilon$, was measured to be $\sim 2 \%$ during actuation of films between -0.5 and $+0.5 \mathrm{~V}$ vs. $\mathrm{Ag} / \mathrm{AgCl}$ reference electrodes in aqueous $1 \mathrm{M} \mathrm{NaPF}_{6}$ electrolyte. This voltage range is well within the safe actuation voltage range [29]. The actuator length is limited to a maximum of between $10 \mathrm{~mm}$ and $35 \mathrm{~mm}$ (set for the specific intravascular application). As was mentioned earlier, the active catheter is encapsulated inside a rigid encapsulation, thus the rigidity requirement of the catheter is satisfied as long as the encapsulation poses rigidities of common cardiovascular catheters (i.e. flexural rigidity of $>22 \times 10^{-6} \mathrm{Nm}^{2}$, the torsional rigidity of $>22 \times 10^{-6} \mathrm{Nm}^{2}$, and the axial rigidity $>450 \mathrm{~N}[16])$.

The rate of actuation of polypyrrole is proportional to the rate of ion insertion, and hence to the current. The current can be limited by the both ionic and electronic resistivities, diffusion coefficients, and the capacitance of the electrodes. For a long device the total polymer resistance along the length of the catheter, $R_{p p y}$, can significantly limit the rate [18], with the predicted time constant being $C_{v}$ is the polymer volumetric capacitance. For a thick device the ionic resistance through the thickness, $t_{p}$, is the rate limiting factor, with the time constant of $\tau=\frac{t_{p}{ }^{2}}{D}$ [18], where $D$ is the effective diffusion coefficient. In electrochemically deposited PPy grown using Yamaura's method diffusion coefficient of $D=5.5 \cdot 10^{-11} \mathrm{~m}^{2} / \mathrm{s}$, and electronic conductivity of $\sigma_{\text {electronic }}=1 \cdot 10^{4} \mathrm{~S} / \mathrm{m}$ were found. These values are fed into the model to help calculate the ion insertion rate and hence predict the actuation speed. According to the model, the desired high speed scanning $(30 \mathrm{~Hz})$ cannot be achieved using these values for the designed geometry. Thus, a geometry optimization was performed using a dynamic electromechanical model, in order to improve the performance of the device at high frequency operation. The model suggests mechanical amplification and electromechanical parameter improvement to achieve the required $1 \mathrm{~mm}$ displacement at high frequency [1] (See Table 1). 
Table 1 : Suggested parameters for high speed actuation [1].

\begin{tabular}{|c|c|c|}
\hline$\varepsilon=4 \%$ & $\mathrm{D}=9 \cdot 10^{-11} \mathrm{~m}^{2} / \mathrm{s}$ & $\sigma_{\text {electronic }}=5 \cdot 10^{4} \mathrm{~S} / \mathrm{m}$ \\
\hline Design & \begin{tabular}{l|l} 
& $@ 30 \mathrm{~Hz}$
\end{tabular} & \begin{tabular}{|l|l}
$10 \mathrm{~Hz}$
\end{tabular} \\
\hline Active Length & $35 \mathrm{~mm}$ & $13 \mathrm{~mm}$ \\
\hline Displacement & $1.0 \mathrm{~mm}$ & $1.0 \mathrm{~mm}$ \\
\hline
\end{tabular}

One approach to achieving the needed displacements at high scan rates is to leave the tip of the catheter uncoated, and simply coat the catheter further down, away from the tip. Thus mechanical amplification is provided by adding a passive length to the active element. Another approach is to increase speed by increasing diffusion coefficient, or reducing the thickness of the active layer [30,31]. The fabrication process can also be modified in order to obtain highly porous polymer, which helps increasing the ion insertion rate. This may, however, reduce the structural rigidity, and therefore careful considerations are required to maintain the specified rigidity as well as high ion diffusion rate. Electronic conductivity of the active element can be enhanced by coating the polymer with a thin metal layer. The metal layer adds to the stiffness of the device and may decrease the degree of catheter bending.

The primary challenge to achieving an effective polypyrrole driven catheter for real time OCT imaging is to demonstrate high speed with reasonable liftetime [1]. The proposed mechanical amplification along with the polymer electrochemical properties' improvement will result in a high speed scanning active catheter suitable for real time imaging applications.

\section{DISCUSSION AND CONCLUSION}

A successful active catheter design comprises a biocompatible, micro-sized, low-cost device with a reasonable response time and certain optimum structural rigidity, which can be actuated under safe operating conditions. Although various active catheters (e.g. shaped memory alloys and polymers (SMA, SMP) driven catheters [5-11], MEMS based devices [3-4] and hydraulically controlled catheters [2]) have been suggested, none of them are in wide spread use due to failure to satisfy the above requirements. Conducting polymer (CP) actuators are suitable candidate for designing active catheters, due to their biocompatibility, low cost, large strain (typically $2 \%$ or greater), low actuation voltage $(<1 \mathrm{~V})$ and ease of fabrication. However electrochemical actuation of these devices involves using ionic electrolytes which require either encapsulation or perhaps direct use of internal fluids. Ionic polymer metal composites (IPMC) based catheters have also been widely studied. These actuators can generate large displacements at relatively low voltages $(<10 \mathrm{~V})$ but their manufacturing process is often relatively expensive and unlike conducting polymers, additional energy is usually consumed to hold the actuator in place. In addition, conducting polymers offer higher stiffness than IPMCs, an attribute which is often important in catheter design. Their efficiency can be higher as maintaining deflection does not require energy expenditure. The speed of conducting polymer actuators is typically slow however (only a few hertz) [19] and, needs to be improved to make possible the rapid scanning used in imaging applications.

The intravascular active catheter [21,22] and the OCT imaging catheter [1] were presented here as the examples of conducting polymer based active catheters. The intravascular catheter provides $\sim 20^{\circ}$ bending angle with a reasonable response time (within few seconds), but its rigidity is low $\left(\sim 0.2 \mathrm{~N} / \mathrm{m}^{2}\right)$. The rigidity can be improved by modifying the polymer synthesis and using conducting polymers in the form of fibres [22]. A more complicated design capable of producing larger angle of bending is also needed in order to access tortuous regions of cardiovascular systems [1]. The OCT imaging catheter requires scanning an optical fibre in 2 dimensions with high speed $(10-30 \mathrm{~Hz})$. The preliminary design was realized by depositing $10 \mu \mathrm{m}$ thick polypyrrole on a commercially available catheter and patterning the polymer using laser machining technique. The primary demonstration of the device was performed with a speed of 10 $\mathrm{Hz}$, and the resulting image quality was comparable with the conventional imaging method. However, the applied actuation potential was high $(10 \mathrm{~V})$ in order to achieve $10 \mathrm{~Hz}$ scanning speed and the number of scanning cycles was limited due to short polymer lifetime at high actuation voltages. Design modification is required in order to achieve both high speed of actuation and the desired polymer life cycle of $>50,000$. According to our model, electrochemical characteristics of the conducting polymer such as electronic conductivity, ionic conductivity and electrochemical strain need to be improved to achieve the desired catheter scanning speed (i.e. $30 \mathrm{~Hz}$ ) for real time imaging. 
The OCT active catheter presented here was particularly designed for intravascular imaging application; however this device can be potentially optimized to be used in other endoscopic procedures such as monitoring gastrointestinal, respiratory, urinary, and reproductive systems.

\section{REFERENCES}

[1] Shoa, T, Madden, J. D., Munce, N. R., Yang, V. XD., [Biomedical applications of electroactive polymer actuators], John Wiley \& Sons, Inc, Chapter 11 (2009).

[2] Haga, Y. and Esashi, M. "Biomedical microsystems for minimally invasive diagnosis and treatment," Proc. IEEE 92, n 1, 98-114 (2004).

[3] Salimuzzaman, A. Matani, O. Oshiro, K. Chihara, M. Asao, "Visualization of a blood vessel using a micromotor," Tech. Dig. 14th Sensor Symp. 279-280 (1996).

[4] Lehr, H., Ehrfeld, W., Hagemann, B.,. Kamper, K.P, Michel, F., Schulz, Ch., Thurigen, Ch., "Development of micro and millimotors," Min. Invas. Ther. Allied Technol. 6, 191-194 (1997).

[5] Ikuta, K., Tsukamoto, M., Hirose, S., "Shape memory alloy servo actuator system with electric resistance feedback and application for active endoscope," Proc. IEEE Int. Conf. Robotics and Automation, 427-430 (1988).

[6] Reynaerts, D., Peirs, J., Brussel, H. V., "Design of a shape memory actuated gastrointestinal intervention system," Proc. 5th Int. Conf. New Actuators, 26-28 (1996).

[7] McCoy, W. C., "Steerable and aimable catheter," U.S. Patent 4543090 (1985).

[8] Kaneto, S., Aramaki, S., Arai, K., Takahashi, Y., Adachi, H., Yanagisawa, K., "Multi freedom tube type manipulator with SMA plate,” Proc. Int. Symp. Microsystems, Intelligent Materials and Robots, 27-29 (1995).

[9] Fukuda, T., S. Guo, Kosuge, K., Arai, F., Negoro, M., Nakabayashi, K., "Micro Active Catheter System with Multi Degrees of Freedom," Proc. IEEE International Conference on Robotic and Automation 3, 2290-2295 (1994).

[10] Metzger, M.F., Wilson, T.S., Schumann, D., Matthews, D.L., Maitland, D.J., "Mechanical properties of mechanical actuator for treating ischemic stroke," Biomedical Microdevices 4, n 2, 89-96 (2002).

[11] Maitland, D.J., Wilson, T., Metzger, M., Schumann, D.L., "Laser-activated shape memory polymer microactuators for treating stroke," Proc. SPIE 4626, 394-402 (2002).

[12] Gue, S., Fukunda, T., Kosuge, K., Arai, F., Oguro, K. and Negoro, M., "Micro Catheter System with Active Guide Wire," Proc. IEEE Intemational Conference on Robotic and Automation 1, 79-84 (1995).

[13] Guo, S., Nakamura, T., Fukuda, T., "Microactive guide wire using ICPF actuator-characteristic evaluation, electrical model and operability evaluation," Proc. IEEE IECON 22nd International Conference on Industrial Electronics, Control, and Instrumentation, 1312-1317 (1996).

[14] Onishia, K., Sewaa, Sh., Asakab, K., Fujiwarab, N., Ogob, K., "Bending Response of Polymer Electrolyte Actuator," Proc. SPIE 3987, Smart Structures and Materials, 121-128 (2000).

[15] American Heart Association., www.americanheart.org

[16] Carey, J., Fahim, A., Munro, M., "Design of braided composite cardiovascular catheters based on required axial, flexural, and torsional rigidities," Journal of Biomedical Materials Research - Part B Applied Biomaterials 70, n 1, 73-81 (2004).

[17] Kalorama Information., "Market for Disposable catheters and suppliers market," Kalorama Information, New York NY. (1996)

[18] Madden, J. D. W., Peter, G. A., Hunter, I. W., "Conducting polymer actuators as engineering materials," Proc. SPIE Smart Structures and Materials: Electroactive Polymer Actuators and Devices, SPIE Press, 176-190 (2002).

[19] Mazzoldi, A., De Rossi, D., "Conductive polymer based structures for a steerable catheter," Proc. SPIE - The International Society for Optical Engineering 3987, 273-80 (2000).

[20] Cohen, Y. B., [Electroactive Polymer (EAP) Actuators as Artificial Muscles: Reality, Potential, and Challenges], Second Edition, SPIE Press Monograph Vol. PM136 (2001).

[21] Della Santa, A., Mazzoldi, A., De Rossi, D., "Steerable microcatheters actuated by embedded conducting polymer structures," Journal of Intelligent Material Systems and Structures 7, n 3, 292-300 (1996).

[22] Santa, D., De Rossi, D., "Intravascular microcatheters steered by conducting polymer actuators," Proc. IEEE Engineering in Medicine and Biology 5, 2203-2204 (1996). 
[23] Tearney, G. J., Brezinski, M. E., Boppart, S. A., Bouma, B. E., Weissman, N., Southern, J. F., Swanson, E. A., Fujimoto, J. G., "Catheter-Based Optical Imaging of a Human Coronary Artery," American Heart association Circulation. 94:3013 (1996).

[24] Huang, D., Swanson, E.A., Lin, C.P., Schuman, J.S., Stinson, W.G., Chang, W., Hee, M.R., Flotte, T., Gregory, K., Puliafito, C.A., Fujimoto. J.G., “Optical Coherence Tomography," Science 254 , 1178 (1991).

[25] Yang, V.X.D., Tang, S.J., Gordon, M.L., Qi, B., Gardinar, G., Kortan, P., Haber, G.B., Kandel, G., Vitkin, I.A., Wilson, B.C., and Marcon, N.E., "Endoscopic Doppler optical coherence tomography: first clinical experience with a novel imaging technique," Gastrointestinal Endoscopy 61, 879-90 (2005).

[26] Yamaura, M., Hagiwara, T., Iwata, K., "Enhancement of electrical conductivity of polypyrrole film by stretching: counter ion effect," Synthetic Metals 26, 209-224 (1988).

[27] Jager, E. W. H., Smela, E., Inganas, O., "Microfabricating Conjugated Polymer Actuators,” Science 290, 1540-1545 (2000).

[28] Munce, N. R., Mariampillai, A., Standish, B., Pop, M., Anderson, K., Liu, G., Luk, T., Courtney, B., Wright, G., Vitkin, I.A., Yang, V.X.D., "Electrostatic Forward-Viewing Scanning Probe for Doppler Optical Coherence Tomography using a Dissipative Polymer Catheter," Optics Letters 33, n 7, 657-9 (2008).

[29] Shoa, T., Cole, M., Yang V.X.D, Madden J.D.W., "Polypyrrole actuator operationg voltage limits in aqueous NaPf6," Proc. SPIE Smart Structures and Materials: Electroactive Polymer Actuators and Devices 6524, 652421 (2007).

[30] Bay, L., West, K., Sommer-Larsen, P., Skaarup, S., Benslimane, M., "A conducting polymer artificial muscle with 12\% linear strain," Advanced Materials 15, 310-313 (2003).

[31] Hara, S., Zama, T., Takashima, W., Kaneto, K., "Free-standing polypyrrole actuators with response rate of $10.8 \%$ s1," Synthetic Metals 149, 199-201 (2005).

[32] Wang, Y., Bachman, M., Li, G.P., Guo, S., Wong, B.J. F., Chen, Z., "Low-voltage polymer-based scanning cantilever for in vivo optical coherence tomography," Optics Letters 30, n 1, 53-55 (2005).

[33] Madden, J.D.W., Vandesteeg, N. A., Anquetil, P. A.; Madden, P. G.A.; Takshi, A., Pytel, R. Z., Lafontaine, S. R., Wieringa, P. A.; Hunter, I. W. "Artificial muscle technology: Physical principles and naval prospects," IEEE Journal of Oceanic Engineering 29, n 3, Biology-Inspired Science and Technology for Autonomous Underwater Vehicles, 706-728 (2004). 